\title{
Caring Behavior of Health Professionals: Its Implication to Clinical Practice
}

\author{
June II A. Kiblasan \\ Dean of Nursing, Mountain Province State Polytechnic College, Bontoc, Mountain Province, Philippines
}

\begin{abstract}
Health professionals' behavior play a vital role in the care patient for it has been assumed that effective behavior promotes a caring relationship leading to an outcome that is therapeutic to both. The purpose of this study was to ascertain the caring behavior demonstrated by the health professionals based on the perspectives of allied health students and its propositions to clinical practice though patients' point of view. Sequential Explanatory Strategy of the mixed method research design was employed where survey and conduct of key informant interview were the strategies employed in the collection of data. Weighted means were used to represent how caring behavior was demonstrated by the health professionals. Independent T-test was utilized to validate the difference of caring behavior demonstrated while thematic data analysis for the data collected during interviews. It was found that caring behaviors of health professionals were demonstrated the same and has no difference. Indeed, caring behavior of academicians is an essential element in developing a learner's personality as future health professional. It is a must to uphold and disseminate the critical aspects of the caring behavior among learners in developing them as future health professional practitioners.
\end{abstract}

Keywords: Health Professionals, Caring behavior, Clinical practice.

\section{Introduction}

Caring emerged as a significant aspect has to possess in response to the environment. It greatly influences how an individual be nurtured and socialize. In education, caring is an approach that is based on reciprocal relationship between the teacher and students on ethical and human principles where caring based interaction of teachers and students' action and feeling are equally considered. ${ }^{1}$ It is widely accepted that good student-teacher relationship is important in increasing students' sense of attachment to school that facilitates academic success. The objective patterns in learning to in planning and development of learning situations applies evidences and instances in educational processes that will help students to have meaningful learning experiences and introduce patterns of caring behavior to students. ${ }^{2}$ At this point, caring as a behavior is essential in promoting the welfare of students. It is a teachinglearning approach that is formed based on constant teacher-student interactions at which, the nature of this educational strategy focuses on caring. ${ }^{1}$ Moreover, previous research finding provides additional insight that teacher's behavior as desired by students contributes to their educational success. ${ }^{3}$

Studies in higher education show the significant of a learning atmosphere that is caring, confident and welcoming are favorable to academic growth for all students. ${ }^{4}$ Moreover, students' achievement of selfesteem and peace reduced anxiety, developing selfesteem and increased the sense of empowerment in students are the outcomes of inducing caring concept in educational system. ${ }^{5}$ Further, instructors' caring behaviors influenced nursing students' caring behaviors positively ${ }^{6}$ and it is most important to show caring as a behavior for it can boost nursing students' interests in learning caring behaviors by incorporating diverse teaching strategies to enhance the effectiveness of caring behaviors. $^{7}$

Moreover, caring relation is an appropriate framework for guiding and creating ethical education ${ }^{8}$ though some health care professionals are comfortable and competent users of technology, they must also preserve a focus on professional-patient relationship 
to achieve quality health care. A relationship that involve reflection on practice to increase recognition and demonstration of caring behaviors ${ }^{9}$ because it was concluded that, caring behavior is essential in clinical practice. ${ }^{7}$ One thing, a study showed that the concept of caring has been applied in designing curriculum based on the concept of caring instrument development and as a criterion to measure caring behavior. ${ }^{10}$

On the other hand, the realization of this craft derived from a belief that effective caring promotes health and a higher level of wellness. It is considered a universal need and an important component in the delivery of health care. However, a study revealed no congruence on the perceptions of nurses and patients when it comes to demonstration of caring behaviors. ${ }^{11}$ This bring additional interest to discover how mentors' caring behavior affect learners as future practitioner.

\section{Method}

Sequential Explanatory Strategy of the mixed method research design was utilized. This method composed of two phases of data gathering that is a combination of quantitative and qualitative strategy. Clustered-purposive-convenience sampling was used for all participants are known and was organized into groups where each group has own part in the accomplishment of this endeavor. It is purposive because the selection of participants was criterion based and convenience for it relied on available allied health students enrolled in Bachelor of Science in Nursing (BSN), Bachelor of Science in Physical Therapy (BSPT), Bachelor of Science in Medical Technology (BSMT) and Bachelor of Science in Respiratory Therapy (BSRT) who were currently enrolled during data gathering, and the patients confined in a healthcare facility during the scheduled data collectionbeing cared by Registered Physical Therapist (RPT), Registered Nurse(RN), Registered
Medical Technologist (RMT) and Registered Radiologic Technologist (RRT). Tools used were self-made Caring Behavior Instrument for students (CBIS) and Caring Behavior Assessment (CBA) tool based from Watson's ten Carative Factors. ${ }^{12} \mathrm{CBA}$ tool was translated to "Ilocano" for it is the common dialect spoken by Cordilleran aside from other local dialects they are using. Both instruments were pretested to determine its reliability making use of Kuder-Richardson 20 (KR20) coefficient and were declared valid for the coefficients of reliability were 0.99 and 0.98 respectively with a descriptive equivalent of "very reliable". Meanwhile, Semi-structured interview guide was also employed to substantiate the findings.

It is a mere fact that statistics is dealing with the collection, analysis, interpretation, presentation and organization of data. ${ }^{13}$ Average weighted mean was used to interpret and analyze the surveyed data and Independent sample $\mathrm{T}$-Test was used to validate differences on caring behavior. Use of words during interview were the basis of analysis where reasoning flows from the words provided by the participants toward themes that are patterned from the data or ideas that were repeated by more than one participant. This reasoning process and inductive thinking guides the organizing, reducing and clustering of data at which once themes are identified, the researcher uses deductive reasoning when considering the fit of data to the themes. ${ }^{14}$

\section{Results and Discussions}

In learning or in practice, caring behavior of mentors or practitioners is an attribute that is essential in dealing with the environment. Table 1 presented how health professionals as mentors demonstrated their caring behavior that is imperative to learner's personality, academic and non-academic achievement for it influences them how to get into it.

Table 1: Caring behavior of health professionals as perceived by allied health students

\begin{tabular}{|l|l|c|c|c|c|c|}
\hline \multirow{2}{*}{ Caring Behavior } & \multicolumn{5}{|c|}{ Academic Program } & \multirow{2}{*}{ Overall } \\
\cline { 3 - 7 } & & RN & RMT & RPT & RRT & \\
\hline \multirow{2}{*}{ Presence } & Mean & 4.16 & 3.87 & 3.54 & 2.87 & 3.61 \\
\cline { 2 - 7 } & DI & FD & FD & FD & FD & FD \\
\hline \multirow{2}{*}{ Guidance } & Mean & 3.84 & 4.23 & 3.23 & 4.11 & 3.85 \\
\cline { 2 - 7 } & DI & FD & CD & OD & FD & FD \\
\hline
\end{tabular}




\begin{tabular}{|c|c|c|c|c|c|c|}
\hline \multirow{2}{*}{\multicolumn{2}{|c|}{ Caring Behavior }} & \multicolumn{4}{|c|}{ Academic Program } & \multirow{3}{*}{$\begin{array}{c}\text { Overall } \\
4.09\end{array}$} \\
\hline & & \multirow{2}{*}{$\begin{array}{l}\mathbf{R N} \\
4.21\end{array}$} & \multirow{2}{*}{$\begin{array}{c}\text { RMT } \\
4.35\end{array}$} & \multirow{2}{*}{\begin{tabular}{r|} 
RPT \\
3.87 \\
\end{tabular}} & \multirow{2}{*}{$\begin{array}{c}\text { RRT } \\
3.92 \\
\end{array}$} & \\
\hline Commetono & Mean & & & & & \\
\hline competence & DI & $\mathrm{CD}$ & $\mathrm{CD}$ & FD & FD & FD \\
\hline \multirow{2}{*}{ Psychosocial support } & Mean & 3.91 & 4.01 & 3.23 & 4.25 & 3.85 \\
\hline & DI & FD & FD & OD & $\mathrm{CD}$ & FD \\
\hline \multirow{2}{*}{ Commitment } & Mean & 4.04 & 4.25 & 4.11 & 4.32 & 4.18 \\
\hline & DI & FD & $\mathrm{CD}$ & FD & $\mathrm{CD}$ & FD \\
\hline \multirow{2}{*}{ Confidence } & Mean & 4.21 & 4.37 & 3.89 & 3.78 & 4.06 \\
\hline & DI & $\mathrm{CD}$ & $\mathrm{CD}$ & FD & FD & $\mathrm{FD}$ \\
\hline \multirow{2}{*}{ Conscience } & Mean & 3.91 & 3.75 & 4.23 & 4.01 & 3.98 \\
\hline & DI & FD & FD & $\mathrm{CD}$ & FD & FD \\
\hline \multirow{2}{*}{ Overall } & Mean & 4.04 & 4.12 & 3.73 & 3.89 & 3.95 \\
\hline & DI & FD & FD & FD & FD & FD \\
\hline
\end{tabular}

Legend: Descriptive Interpretation (DI); Average Weighted Mean (MEAN); 4.20 - $5.00=$ Constantly Demonstrated (CD); 3.40 - 4.19 $=$ Frequently Demonstrated (FD); $2.60-3.39=$ Occasionally Demonstrated (OD); $1.80-2.59$ = Rarely Demonstrated (RD); $1.00-1.79$

$=$ Scarcely Demonstrated (SD)

There were seven identified caring behaviors of mentors extended to learners. These are presence, guidance, competence, psychosocial support, commitment, confidence and conscience which was generally perceived as frequently demonstrated. Learners perceived that mentors were committed greatly in teaching with competence and confidence. Their moral as a mentor always touches their conscience leading them to properly guide and sparingly support their learners' psychosocial wellbeing. However, there presence is minimal due to their complex responsibilities as educator. This result corroborates with the level of nursing instructors' caring behavior during teaching students was medium to high with the mean and standard deviation of 4.65 which means that clinical instructors deeply cared for their students. ${ }^{15}$ However, looking into consideration the weighted means of the findings, commitment of mentors was nearly to be constantly demonstrated. Studies in higher education show the significant of a learning atmosphere that is caring, confident and welcoming and favorable to academic growth for all students. The pedagogic context of caring involved developing rapport and going out of one's way to provide learning experiences geared toward students' attributes while in caring-based interactions, the actions and feelings of instructors and students are considered equally. ${ }^{16}$ These literatures proved commitments of the mentors. Moreover, the findings itself reflected that each academic program had their own focus of learning needs and observations as to caring capabilities of their mentors. This can be a good indicator in deciding what attitude and strategy or method in teaching or educating learners to be inculcated in mentoring.

On the other hand, Table 2 revealed how health professionals as clinician demonstrated their caring behaviors to their patients.

Table 2: Caring behavior of allied health professionals as perceived by patients in a healthcare facility

\begin{tabular}{|c|c|c|c|c|c|c|}
\hline \multirow{2}{*}{\multicolumn{2}{|c|}{ Caring Behavior }} & \multicolumn{4}{|c|}{ Profession } & \multirow{3}{*}{$\begin{array}{c}\text { Overall } \\
3.73\end{array}$} \\
\hline & & \multirow{2}{*}{$\frac{\mathbf{R N}}{4.14}$} & \multirow{2}{*}{$\begin{array}{c}\text { RMT } \\
3.50\end{array}$} & \multirow{2}{*}{$\begin{array}{r}\text { RPT } \\
4.12\end{array}$} & \multirow{2}{*}{$\frac{\text { RRT }}{3.15}$} & \\
\hline Humanism/Faith-Hope/ & Mean & & & & & \\
\hline Sensitivity & DI & FD & FD & FD & OD & FD \\
\hline
\end{tabular}




\begin{tabular}{|c|c|c|c|c|c|c|}
\hline \multirow{2}{*}{\multicolumn{2}{|c|}{ Caring Behavior }} & \multicolumn{4}{|c|}{ Profession } & \multirow{3}{*}{$\begin{array}{c}\text { Overall } \\
3.50\end{array}$} \\
\hline & & \multirow{2}{*}{$\frac{\mathbf{R N}}{2.74}$} & \multirow{2}{*}{$\frac{\text { RMT }}{2.70}$} & \multirow{2}{*}{$\frac{\text { RPT }}{3.67}$} & \multirow{2}{*}{$\frac{\text { RRT }}{4.87}$} & \\
\hline & Mean & & & & & \\
\hline 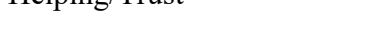 & DI & OD & OD & FD & $\mathrm{CD}$ & FD \\
\hline \multirow{2}{*}{$\begin{array}{l}\text { Expression of positive or } \\
\text { negative feelings }\end{array}$} & Mean & 3.41 & 3.22 & 2.74 & 3.86 & 3.31 \\
\hline & DI & FD & OD & OD & FD & OD \\
\hline \multirow{2}{*}{ Teaching/Learning } & Mean & 4.45 & 3.67 & 4.36 & 3.12 & 3.90 \\
\hline & DI & $\mathrm{CD}$ & FD & $\mathrm{CD}$ & OD & FD \\
\hline \multirow{2}{*}{$\begin{array}{l}\text { Supportive/Protective/ } \\
\text { Corrective Environment }\end{array}$} & Mean & 3.49 & 2.74 & 4.68 & 4.87 & 3.95 \\
\hline & DI & FD & OD & $\mathrm{CD}$ & $\mathrm{CD}$ & FD \\
\hline \multirow{2}{*}{ Human needs assistance } & Mean & 4.62 & 2.54 & 4.83 & 3.11 & 3.78 \\
\hline & DI & $\mathrm{CD}$ & $\mathrm{RD}$ & $\mathrm{CD}$ & OD & FD \\
\hline \multirow{2}{*}{$\begin{array}{l}\text { Existential/ } \\
\text { Phenomenological Spiritual } \\
\text { forces }\end{array}$} & Mean & 3.58 & 2.15 & 3.12 & 4.21 & 3.27 \\
\hline & DI & FD & $\mathrm{RD}$ & OD & $\mathrm{CD}$ & OD \\
\hline \multirow{2}{*}{ Overall } & Mean & 3.86 & 3.02 & 3.99 & 3.79 & 3.66 \\
\hline & DI & FD & OD & FD & FD & FD \\
\hline
\end{tabular}

Legend: Descriptive Interpretation (DI); Average Weighted Mean (MEAN); 4.20 - 5.00 = Constantly Demonstrated (CD); 3.40 - 4.19 $=$ Frequently Demonstrated (FD); $2.60-3.39=$ Occasionally Demonstrated (OD); $1.80-2.59=$ Rarely Demonstrated $(\mathrm{RD}) ; 1.00-1.79$ $=$ Scarcely Demonstrated (SD)

As gleaned from the table, the seven scales on how a health practitioner exhibits caring to their patients. Generally, it was perceived as frequently demonstrated which the same with the mentors is. This shows that health care professionals regularly, routinely or oftentimes perform these caring behaviors to their patients. However, the result of this study negates the finding of a study that recommends empowering nurses to engage in positive health behavior through education. ${ }^{17}$

Moreover, health trend now is to foster a healthy, safe and supportive environment. Everywhere people go especially in healthcare facilities, signs of safety first are posted. However, from the seven scales of caring behaviors, only six were demonstrated frequently that is something to look upon. Expression of positive or negative feelings and existential/phenomenological/ spiritual was the one perceived as occasionally demonstrated. Existential can be a reference to survival while phenomenology is the inquiries that addresses the practices of professionals in everyday life and spiritual force is the faith to practice profession. This is somewhat unbelievable because this is referring to sincerity and commitment of a health professionals related the services they can give to their patients.

To validate if there is an implication of the caring behavior of health educators in the academe on how health practitioners exercise their vocation in the clinical area, independent sample t-test was used. The caring behavior of health professional were fully demonstrated as perceived by students and patients. Table 3 presented the inference if there is significant difference on caring behaviors of health care professionals that implicates clinical practice. As gleaned from the table, caring behavior of health academician $(\mathrm{M}=3.95, \mathrm{SD}$ $=1.72, \mathrm{~N}=4$ ) was not significantly different from the health practitioners $(\mathrm{M}=3.86, \mathrm{SD}=0.09, \mathrm{~N}=4)$, $\mathrm{t}$-value $=2.664, \mathrm{p}=0.154$. 
Table 3: Significant difference on perceived caring behavior of health professionals

\begin{tabular}{|l|c|c|c|c|}
\hline Health Professionals & Student & Patients & t & p-value \\
\hline Registered Nurse (RN) & 4.04 & 3.86 & & \\
\cline { 1 - 3 } Registered Medical Technologist (RMT) & 4.12 & 3.82 & \multirow{2}{*}{2.664} & \multirow{2}{*}{0.154} \\
\cline { 1 - 3 } Registered Physiotherapist (RPT) & 3.73 & 3.99 & & \\
\cline { 1 - 3 } Registered Radiologic Technologist (RRT) & 3.89 & 3.79 & & \\
\hline
\end{tabular}

The finding revealed that, how a learner be educated depicts how they will practice their profession in the future. The good portrayal of caring behaviors by the educators to their learners will determine how learners be molded that will affect how they will practice after graduation. This is because of its influence that is crucial to the learning process. One thing, caring behavior is imperative to learner's personality, academic and nonacademic achievement for it influences them how to get into it. That influence will implicate how they will practice once they will graduate.

To substantiate the interpreted and analyzed numerical data, ten patients from the respondents in the quantitative part of this study were subjected to follow-up interview after confirmation of participation. Patients were asked about their experiences and the traits they observed from the health professionals during interaction that made them listen, participate and follow instructions. Responses were transcribed as basis in coming up with initial coding and was categorized. Finally, three categories were foster wellbeing, ensuring proficiency and patient's engagement while the themes drawn were human needs assistance, competence, commitment and psychosocial support.

The findings show a good impact and proves that "how an individual be learned and nurtured depicts how they will perform". However, it is still a need to constantly demonstrate those caring behaviors for it was suggested that health education should be delivered to patients according to their learning style in order for patients to comprehend and retain information provided. ${ }^{18}$

\section{Conclusion and Recommendation}

The findings show a good impact and proves that "how an individual be learned and nurtured depicts how they will perform in the future". Therefore, demonstration of caring behaviors is fundamental to uphold to learners for it significantly contribute a great impact on their behavior as future professional in the healthcare arena. One thing, caring behavior of health professionals as academician is an essential element of developing a student's personality as future health professional practitioners. Thus, it is highly recommended to uphold and disseminate the critical aspects of caring behaviors among learners in developing them as future health professional practitioners.

Conflict of Interest: There is no professional, personal or family allegiance, bias, inclination, obligation or loyalty which may in any way affects the objectivity, independence or impartiality in the accomplishment of this study.

Funding: This research did not receive any specific grant from funding agencies in the public, commercial, or non-for-profit sectors.

Ethical Clearance: Guidelines for the protection of human rights outlined in the American Nurses Association ${ }^{19}$ was observed.

\section{References}

1. Salehian M, Heydari A, Aghebati N \& Moonaghi HK. Faculty-Student Caring Interaction in Nursing Education: An Integrative Review., JCaring Sci. 2017, 6(3), 257-267., doi:10.15171/jcs.2017.025., http://journals.tbzmed.ac.ir/JCS

2. Guo Y, Shen J, Ye X, Chen H, Jiang A. The design and testing of a caring teaching model based on the theoretical framework of caring in the Chinese Context: a mixed-method study. Nurse Educ Today 2013; 33(8): 912-8. doi: 10.1016/j. nedt.2012.08.005.

3. Wilkins J. The Development of a Scale to Explore the Multidimensional Components of Good StudentTeacher Relationships, Edu Res Perspective. Int J. Volume 41, 2014, Pages 154-172

4. Burger KG, Kramlich D, Malitas M, Page-Cutrara 
$\mathrm{K} \&$ Whitfield-Harris L. Application of the symphonological approach to faculty-to-faculty incivility in nursing education. J Nurs Educ 2014; 53 (10): 563-8. doi: 10.3928/01484834-2014092202.

5. Rudolfsson G, Berggren I. Nursing students' perspectives on the patient and the impact of the nursing culture: a meta-synthesis. J Nurs Manag 2012; 20(6): 771-81. doi: 10.1111/j.1365-2834. 2012.01470.x.

6. Labrague LJ, McEnroe-Petitte DM, Papathanasiou IV, Edet OB, Arulappan J. Impact of Instructors' Caring on Students' Perceptions of Their Own Caring Behaviors. J Nurs Scholars 2015 Jul: 47(4):338-46. doi: 10.1111/jnu.12139.

7. Li YS, Yu WP, Yang BH, Liu CF. A comparison of the caring behaviors of nursing students and registered nurses: Implications for nursing education, J Clin Nurs 2016 Nov;25 (21-22):33173325. doi: 10.1111/jocn.13397. Epub 2016 Sep 9.

8. Mixer SJ, McFarland MR, Andrews MM, Strang CW. Exploring faculty health and wellbeing: creating a caring scholarly community. Nurse Educ Today 2013; 33 (12): 1471-6. doi: 10.1016/j.nedt. 2013. 05.019.

9. Greger J. "Facilitating Caring Behaviors in Technology-Dependent Nursing Practice Through the use of Simulation Training and Confluent Education Strategies". Master of Arts in Nursing Theses (2012).

10. Zareh Hoshyari Khah H, Moradbeygi K, Elhami S, Shayesteh far M, Cheraghian B, Hatefi Moadab N. Impact of a Caring Behavior Educational Program Based on Human Care Theory on Nursing Students' Perception of the Care. Iranian J Med Edu 2015; 14 (10): 836-846. URL: http://ijme.mui.ac.ir/article-13426-en.html
11. Papastavrou E, Charalambous A \& Efstathiou G. Nurses and patients' perceptions of caring behaviors: Quantitative systematic review of comparative studies. J Ad Nur, Wiley, 2011, 67 (6), pp. 1191.

12. Cronin SN \& Lee B (2009). Caring behaviors assessment tool. In J. Watson (Ed.), Assessing and measuring caring in nursing and health science (2nd Ed.). New York: Springer: 2009.

13. Romijn JA (2014). "Philosophy of statistics." Stanford Encyclopedia of Philosophy. 2014

14. Creswell JW. Qualitative inquiry and research design: Choosing among five approaches ( $3^{\text {rd }} \mathrm{ed}$.). Thousand Oaks, CA: SAGE: 2013.

15. Zamanzadeh V, Shohani M \& Palmeh T. Nursing Students' Perception of Instructors' Caring Behaviors in Tabriz University of Medical Sciences. J Caring Sci 2015-4(1), 55-62. http://doi. org $/ 10.5681 /$ jcs. 2015.006

16. Begum S \& Slavin H. Perceptions of "caring" in nursing education by Pakistani nursing students: an exploratory study. Nurse Educ Today 2012; 32 (3): 332-6. doi: 10.1016/j.nedt.2011.10.011.

17. Kiguhe Nebert M, M. Okello Agina B \& Yitambe A. Health Behaviour among Nurses Working in Public Hospitals in Kakamega County, Kenya. Nur Res Prac 2017. 1-8. 10.1155/2017/4683189.

18. Grebner LA. Addressing learning style needs to improve effectiveness of adult health literacy education, Int $\mathbf{J}$ Heal Sci, American Research Institute for Policy Development. March 2015, Vol. 3, No. 1, pp. 93-106., DOI: 10.15640/ijhs.v3n1a6., URL: http://dx.doi.org/10.15640/ijhs.v3n1a6

19. Wood GL, Haber J. Nursing research method critical appraised and utilization. St. Louis, Missouri: Mosby, Inc.; 2002. 